\title{
Design and Implementation of LED Solar Simulator
}

\author{
${ }^{1}$ AHMED SAMIR, ${ }^{2}$ ABDELMOMEN MAHGOUB,${ }^{1}$ AREF ELIWA,,${ }^{1}$ DOAA M. ATIA, \\ ${ }^{1}$ HANAA T. EL- MADANY, ${ }^{2}$ KHALED EL-METWALLY AND ${ }^{3}$ MOHAMED ZAHRAN \\ ${ }^{1}$ Photovoltaic Department, ${ }^{2}$ Electrical Power and Machines \\ ${ }^{1}$ Electronics Research Institute, ${ }^{2}$ Faculty of Engineering, ${ }^{3}$ National Authority for Remote Sensing \\ \& Space Sciences \\ ${ }^{1}$ Joseph Tito-Haykestep, ${ }^{2}$ Cairo University, ${ }^{3}$ Joseph Broz Tito \\ ${ }^{1}$ Nozha Division-Cairo Governorate-Egypt, ${ }^{2}$ Giza - Egypt, ${ }^{3}$ El-Nozha El-Gedida, Cairo, EGYPT
}

\begin{abstract}
In this paper, a complete LED-based solar simulator prototype is designed and implemented. The proposed light source of this solar simulator is formed using only six different types of LEDs to simulate the AM 1.5G spectrum. In addition, the flyback converter is designed to provide the required power of the solar simulator. In order to monitor and adjust the temperature at Standard Test Conditions (STC) of $25{ }^{\circ} \mathrm{C}$, a proposed PID controller is applied and implemented using Arduino Mega 2560. The LED-based solar simulator prototype implementation has been achieved. The performance of the solar simulator prototype has been verified and tested.
\end{abstract}

Key-Words: - Solar simulator - Solar cells - Standard Test Conditions - LEDs - Flyback converter - Temperature control - PID controller

Received: September 25, 2019. Revised: April 9, 2020. Accepted: April 17, 2020. Published: April 30, 2020.

\section{Introduction}

Due to declining the fossil fuels and increasing the global warming, the sustainable energy sources such as wind and solar oriented are gaining more consideration as substitute sources of energy [1]. Clean energy is imperative for the outlook of our planet. The sun is the best natural accessible energy provenance that we have. Photovoltaic (PV) solar cells transform the energy of the sun into electricity at continual improvement efficiencies. Mainstream technologies exhibit close to $20 \%$ efficiencies whereas record efficiencies have surpassed $40 \%$ showing the potential for further technological advancement and increase in efficiency. They can be actively used across the planet since they can work under various ratios of diffuse and direct sunlight. The PV market of thin-film solar cells was valued at \$11.421 million in 2016 and is anticipated to grow, with an annual growth rate of $19.4 \%$ from 2017 to 2023 , to arrive $\$ 39.512$ million by 2023 , in conformity with PV market coalition. The research on new solar cells is presently concentrated on organic, perovskite, and multi-junction solar cells [2].

As a consequence of the increased use of solar energy across the globe, high quality characterization of PV modules for accurate power rating and energy yield forecasting measurements is crucial and more essential than ever. The I-V characteristics of PV cells and modules can be measured under any conditions but the efficient data should be gauged under special condition is called STC. At STC, the irradiance is $1000 \mathrm{~W} / \mathrm{m}^{2}$, the temperature is $25^{\circ} \mathrm{C}$, the AM $1.5 \mathrm{G}$ solar spectrum and normal incidence. There are different characterization methods, either outdoors or indoors. The outdoor test is not favorite due to change factors such as the spectral distribution of solar radiation, the intensity and geographical location time, day of the year, climate conditions, the composition of the atmosphere, variation in altitude, and weather conditions [3]. The indoor characterization methods are easier to be used in production lines as they are faster and weather independent. The best solution to avoid the problems of outdoor testing is testing the solar cells at any time in the laboratory use of the so-called solar simulator [4].

A solar simulator is a device that gives spectral composition and intensity almost the natural light of the sun [4]. The solar simulator is a controllable indoor test facility offering laboratory conditions used to measure the functioning of solar cells, PV modules, and other devices and substances which are delicate to sunlight. The solar simulator is formed from light sources which used to simulate the spectrum of the sun and linked to the power 
supply to operate the system, optics and filters used to amendment the output rays of the light source to provide the required irradiance, and control system to work the solar simulator [5-6].

There are several common light sources which used in the solar simulator to test solar cells and modules such as carbon arc lamps, quartz- tungsten halogen lamps, mercury xenon lamps, xenon arc lamps, metal halide lamps, and LED lamps. Xenon arc lamps are the most widely used as a light source in solar simulators, while metal halide arc lamps, carbon arc lamps, and quartz tungsten halogen lamps are also selected as the light source in particular types of solar simulator designs [2], [5], [7]. Recently, more research done using LED as a light source due to their advantages compared with traditional light sources such as its lower cost, more compact, less power consumption and so on [2-5], [8-10].

This paper proceeds as follows: Section 2 illustrates the LED based solar simulator design including light source, power supply, and temperature control. Section 3 shows the experimental results of the LED solar simulator prototype, including the power supply current and voltage waveforms, and the output spectrum of LEDs for the solar simulator. Finally, Section 4 gives paper conclusion.

\section{LED based Solar Simulator Design}

The following sections give the detailed design of the proposed solar simulator:

\subsection{Design of Solar Simulator Light Source}

The objective of the LED solar simulator presented in this paper is to simulate the AM $1.5 \mathrm{G}$ spectrum with the characteristics that have been presented previously in [4]. The solar irradiance in the wavelength from $400 \mathrm{~nm}$ to $1100 \mathrm{~nm}$ is calculated by integrating the standard of the solar spectrum, resulting in an approximate value of 755 $\mathrm{W} / \mathrm{m}^{2}[11]$.

By the knowledge of the solar irradiance and the test plane area, the required radiant flux incident on the working area can be calculated as [11]:

$$
\Phi_{e}=E_{e} \times A
$$

Where $\Phi_{\mathrm{e}}$ is the required radiant flux, $\mathrm{E}_{\mathrm{e}}$ is the integrating of solar irradiance from $400 \mathrm{~nm}$ to 1100 , and $\mathrm{A}$ is the tested area.
The total required flux to design the proposed solar simulator with a test plane area (A) of $5 \times 5 \mathrm{~cm}^{2}$ is $1.887 \mathrm{~W}$. To validate the spectrum of solar simulator, it should be divided into six intervals from 400 to $1100 \mathrm{~nm}$ according to IEC 60904-9 as shown in Table 1 [11]. Consequently, the required flux in the interval of $400-500 \mathrm{~nm}$ is $0.347 \mathrm{~W}$. In addition, $0.376 \mathrm{~W}$ is the required flux from $500 \mathrm{~nm}$ to $600 \mathrm{~nm}$. Furthermore, the required flux of 600$700 \mathrm{~nm}, 700-800 \mathrm{~nm}, 900-1000 \mathrm{~nm}$, and 1000-1100 $\mathrm{nm}$ are $0.347 \mathrm{~W}, 0.281 \mathrm{~W}, 0.236 \mathrm{~W}$, and $0.300 \mathrm{~W}$, respectively.

The proposed light source of LED solar simulator is constructed from different types of high power LEDs in order to provide a spectrum matched the AM 1.5G spectrum of the sun. A set of cool white LEDs (LZ4-00CW08) is selected to cover the spectral range from $400 \mathrm{~nm}$ to $600 \mathrm{~nm}$, which provided all required radiation in 500-600 nm spectral range, and it also contributed most of the required optical power from $400-500 \mathrm{~nm}$ spectral range. The remainder of the spectral from $400 \mathrm{~nm}$ to $500 \mathrm{~nm}$ is provided by blue LED (LZ4-00B208). In addition, the main light source in the spectral range from $600 \mathrm{~nm}$ to $700 \mathrm{~nm}$ is the deep red LEDs (LZ400R208). However, a part of spectral range from $600 \mathrm{~nm}$ to $700 \mathrm{~nm}$ is supplemented by the cool white LEDs. Moreover, far-red LEDs (LZ400R308) is cover the spectral range from $700 \mathrm{~nm}$ to $800 \mathrm{~nm}$ range, whereas infra-red (LZ4-00R408) and (LZ4-00R708) LEDs are used to cover the spectral ranges from $800 \mathrm{~nm}$ to $900 \mathrm{~nm}$ and from $900 \mathrm{~nm}$ to $1100 \mathrm{~nm}$, respectively.

Table 1. The radiant flux requirements for class A spectral match

\begin{tabular}{|c|c|c|}
\hline $\begin{array}{c}\text { Wavelength } \\
\text { [nm] }\end{array}$ & AM 1.5G & $\begin{array}{c}\text { Required } \\
\text { flux in each } \\
\text { interval }\end{array}$ \\
\hline $300-400$ & no spec & no spec \\
\hline $400-500$ & $18.4 \%$ & 0.347 \\
\hline $500-600$ & $19.9 \%$ & 0.376 \\
\hline $600-700$ & $18.4 \%$ & 0.347 \\
\hline $800-900$ & $14.9 \%$ & 0.281 \\
\hline $900-1000$ & $12.5 \%$ & 0.236 \\
\hline $1000-1100$ & $15.9 \%$ & 0.300 \\
\hline $1100-1400$ & no spec & no spec \\
\hline
\end{tabular}

The spectral output of the colored LEDs based on their datasheet values is approximated using the Gaussian function as follows [9]: 


$$
f(x)=P e^{-\frac{1}{2}\left(\frac{\lambda-C W L}{\sigma}\right)^{2}}
$$

Where, $\mathrm{P}$ is the radiant flux curve peak of LED and the mean value is equal to central wavelength (CWL), $\lambda$ is the wavelength, and $\sigma$ is the standard deviation.

The standard deviation depends on the Full Width Half Maximum (FWHM) as follows [9]:

$$
\sigma=\frac{F W H M}{2 \sqrt{2 \ln (2)}}
$$

A MATLAB software program is written to simulate the different LED spectral based on the mathematical model of LED. Figure 1 gives the output spectral of each LED and the total output spectral of proposed simulator.

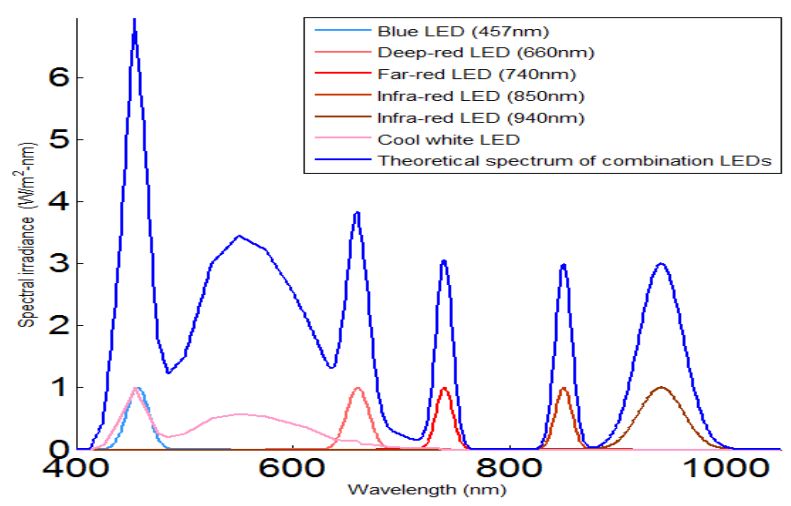

Fig.1: Simulation of the proposed various kinds of LEDs

\subsection{Design of the Power Supply}

The main components of the proposed power supply are bridge rectifier, and DC-DC converter. There are some various options of how to create the DC-DC converter. Some are very simple and others have very complex structures [12]. Due to the simplicity, ease of design, and low cost, a proposed flyback converter is selected to provide the needed power to operate the solar simulator. The flyback converter is the most common power-supply topology for low power applications less than 200W [13]. A flyback converter is similar to any converters it has two operating modes, which are discontinuous conduction mode (DCM) and continuous conduction mode (CCM). In CCM a portion of the energy is stored in the flyback transformer still in the transformer when the next
ON period begins whereas in DCM the entire energy stored in the transformer is moved to the load during the OFF period. Otherwise, the third mode is the boundary between CCM and DCM.

There are benefits of using CCM flyback converter such as small ripple and rms current, lower MOSFET conduction loss, lower primary MOSFET turn-off loss, low core loss, lower capacitor dissipation, and smaller EMI filter and output filter [14]. Because of these benefits, a proposed CCM flyback is selected to provide the needed power of LED solar simulator. The power supply is designed to operate in a wide range of input voltage range of 85-230 V and 170.4 W of output power. The specifications of the proposed power supply which used in the design are given in Table 2.

Table 2. Input $\&$ output specifications for the

\begin{tabular}{|c|c|}
\hline Parameter & Value \\
\hline Maximum $\mathrm{AC}$ input voltage, $\mathrm{V}_{\mathrm{ac}}^{\max }$ & $230 \mathrm{~V}$ \\
\hline age, $V_{a c}^{\min }$ & $85 \mathrm{~V}$ \\
\hline $\operatorname{Max}$ & $170.4 \mathrm{~W}$ \\
\hline Supply & $50 \mathrm{~Hz}$ \\
\hline Converter efficiency assum & $85 \%$ \\
\hline
\end{tabular}
proposed power supply design

Several steps to design the power supply are followed as:

\subsubsection{Input Component Value Calculation}

Step 1: Calculate the input power

$$
P_{i n}=\frac{P_{o}}{\eta}=200.470 \mathrm{~W}
$$

Step 2: Calculate the DC-link capacitor

By using a bridge rectifier, the voltage is converted from $\mathrm{AC}$ to $\mathrm{DC}$. The $\mathrm{DC}$-link capacitor $\left(\mathrm{C}_{\mathrm{dc}}\right)$ is used to smooth the output voltage of rectification. Typically, the DC link capacitor is selected as $2-3 \mu \mathrm{F}$ per watt of input power for universal input range (85 265Vrms) and $1 \mu \mathrm{F}$ per watt of input power for European input range (195 265Vrms) as $[13,15]$ :

$$
C_{d c}=2 \times 10^{-6} \times P_{i n} \cong 400 \mu F
$$

Step 3: Calculate minimum DC input voltage and maximum DC input voltage

$$
V_{d c}^{m i n}=\sqrt{2 \times\left(V_{a c}^{m i n}\right)^{2}-\frac{P_{i n} \times\left(1-D_{c h}\right)}{C_{d c} \times F_{l}}}=80.19 \mathrm{~V}
$$




$$
V_{d c}^{\max }=\sqrt{2} V_{a c}=325.26 \mathrm{~V}
$$

\subsubsection{Selection of the IGBT}

The maximum collector to emitter voltage can be calculated as:

$$
V_{c e}^{\max }=V_{d c}^{\max }+V_{r}+V_{\text {spike }}
$$

$$
\text { Choose } \mathrm{V}_{\mathrm{ce}}{ }^{\max }=600 \mathrm{~V} \text {. }
$$

Where $\mathrm{V}_{\text {spike }}$ is voltage due to leakage inductance of the transformer, which at the starting point is $30 \%$ of the $\mathrm{V}_{\mathrm{ce}}{ }^{\max }$ and $\mathrm{V}_{\mathrm{r}}$ is reflected voltage at the primary of the transformer which is normally from $60 \mathrm{~V}$ to $90 \mathrm{~V}$ for a wide range of input $[13,15]$.

\subsubsection{Design of the Transformer}

The transformer is the main part of the flyback converter, which designed to provide three output voltages of $120 \mathrm{~V}, 90 \mathrm{~V}$, and $12 \mathrm{~V}$ to feed the load of $0.8 \mathrm{~A}, 0.8 \mathrm{~A}$, and $0.2 \mathrm{~A}$ respectively. The required specification for the transformer design is given by Table 3

Table 3. Design parameters of the transformer

\begin{tabular}{|c|c|}
\hline Parameter & Value \\
\hline Input voltage $\left(\mathrm{V}_{\mathrm{in}}\right)$ & $311 \mathrm{~V}$ \\
\hline Output voltage \#1 ( $\left.\mathrm{V}_{\mathrm{o} 1}\right)$ & $120 \mathrm{~V}$ \\
\hline Output current \#1 $\left(\mathrm{I}_{\mathrm{o} 1}\right)$ & $0.8 \mathrm{~A}$ \\
\hline Output voltage \#2 ( $\left.\mathrm{V}_{\mathrm{o} 2}\right)$ & $90 \mathrm{~V}$ \\
\hline Output current \#2 $\left(\mathrm{I}_{\mathrm{o} 2}\right)$ & $0.8 \mathrm{~A}$ \\
\hline Output voltage \#3 ( $\left.\mathrm{V}_{\mathrm{o} 3}\right)$ & $12 \mathrm{~V}$ \\
\hline Output current \#3 $\left(\mathrm{I}_{03}\right)$ & $0.2 \mathrm{~A}$ \\
\hline Frequency $(\mathrm{f})$ & $10 \mathrm{kHz}$ \\
\hline Regulation $(\alpha)$ & $0.5 \%$ \\
\hline Diode voltage drop $\left(\mathrm{V}_{\mathrm{d}}\right)$ & $0.7 \mathrm{~V}$ \\
\hline Operating flux density $\left(\mathrm{B}_{\mathrm{ac}}\right)$ & $0.25 \mathrm{~T}$ \\
\hline Core Material & Ferrite \\
\hline Window utilization $\left(\mathrm{K}_{\mathrm{u}}\right)$ & 0.4 \\
\hline Temperature rise goal $\left(\mathrm{T}_{\mathrm{r}}\right)$ & $30^{\circ} \mathrm{C}$ \\
\hline
\end{tabular}

Steps of the transformer design are followed as:

Step 1: Calculate the total apparent power, $\mathrm{P}_{\mathrm{t}}$.

$$
P_{t}=P_{t p}+P_{t s}=373.612 \mathrm{~W}
$$

Step 2: Calculate the electrical conditions, $\mathrm{K}_{\mathrm{e}}$.

$$
\mathrm{K}_{\mathrm{e}}=0.145 \times \mathrm{K}_{\mathrm{f}}^{2} \times \mathrm{f}^{2} \times \mathrm{B}_{a c}{ }^{2} \times 10^{-4}=1450
$$

Where $\mathrm{K}_{\mathrm{f}}$ is the waveform factor which equal to 4 for a square wave and equals to 4.44 for a sine wave [16].

Step 3: Calculate the core geometry, $\mathrm{K}_{\mathrm{g}}$.

$$
\mathrm{K}_{g}=\frac{\mathrm{P}_{\mathrm{t}}}{2 \mathrm{~K}_{\mathrm{e}} \varepsilon} \times 1.35=0.348 \mathrm{~cm}^{5}
$$

Operating at $10 \mathrm{kHz}$, and the skin effect, the overall window utilization, $\mathrm{K}_{\mathrm{u}}$, reduced. To return the design back to the norm, the core geometry, $\mathrm{K}_{\mathrm{g}}$, should be multiplied by 1.35 [17].

Step 4: Select the core of the transformer.

The ETD-59 core is selected with specification demonstrated in Table 4

Table 4. Specification of the ETD-59 core

\begin{tabular}{|c|c|}
\hline Core number & ETD-59 \\
\hline Manufacturer & Ferroxcube \\
\hline Magnetic path length, MPL & $13.90 \mathrm{~cm}$ \\
\hline Window height, $\mathrm{G}$ & $4.500 \mathrm{~cm}$ \\
\hline Core weight, $\mathrm{W}_{\text {tfe }}$ & 250 grams \\
\hline Copper weight, $\mathrm{W}_{\text {tcu }}$ & $237.7 \mathrm{grams}$ \\
\hline Mean length turn, MLT & $12.9 \mathrm{~cm}$ \\
\hline Iron area, $\mathrm{A}_{\mathrm{C}}$ & $3.677 \mathrm{~cm}^{2}$ \\
\hline Window area, $\mathrm{W}_{\mathrm{a}}$ & $5.186 \mathrm{~cm}^{2}$ \\
\hline Area product, $\mathrm{A}_{\mathrm{p}}$ & $19.0698 \mathrm{~cm}^{4}$ \\
\hline Core geometry, $\mathrm{K}_{\mathrm{g}}$ & $2.1271 \mathrm{~cm}^{5}$ \\
\hline Surface area, $\mathrm{A}_{\mathrm{t}}$ & $163.1 \mathrm{~cm}^{2}$ \\
\hline Millihenrys per 1000 turns, $\mathrm{AL}$ & 27 \\
\hline
\end{tabular}

Step 5: Calculate the number of primary turns, $N_{p}$, using Faraday's Law.

$$
N_{p}=\frac{\mathrm{V}_{i n} \times 10^{4}}{\mathrm{~K}_{\mathrm{f}} \times \mathrm{B}_{\mathrm{ac}} \times \mathrm{f} \times \mathrm{A}_{\mathrm{c}}}=85 \text { turns }
$$

Step 6: Calculate the current density, J, using a window utilization, $\mathrm{K}_{\mathrm{u}}=0.29$.

$$
J=\frac{P_{t} \times 10^{4}}{K_{f} \times K_{u} \times B_{a c} \times f \times A_{p}}=68 \mathrm{~A} / \mathrm{cm}^{2}
$$

Step 7: Calculate the input current, $I_{\text {in. }}$.

$$
I_{i n}=\frac{P_{o}}{V_{i n} \times \eta}=0.649 \mathrm{~A}
$$

Step 8: Calculate the primary bare wire area, $\mathrm{A}_{\mathrm{wp}(\mathrm{B})}$.

$$
A_{w p(B)}=\frac{I_{i n}}{J}=0.009 \mathrm{~cm}^{2}
$$

Step 9: Calculate the required number of primary strands, $S_{\text {np }}$. 


$$
S_{n p}=\frac{A_{w p}(B)}{\begin{array}{c}
\text { Bare area of selected } A W G \\
\text { use } S_{n p}=1
\end{array}}=0.73
$$

Where the American Wire Gauge (AWG) selected in this design is equal to 16 , the characteristics of AWG 16 is illustrated in [16].

Step 10: Calculate the number of each secondary turns, $\mathrm{N}_{\mathrm{s} \mathrm{n}}$.

$$
N_{s n}=\frac{N_{p} \times V_{s n}}{V_{i n}} \times\left(1+\frac{\alpha}{100}\right)
$$

Where $\mathrm{N}_{\mathrm{s} 1}, \mathrm{~N}_{\mathrm{s} 2}$, and $\mathrm{N}_{\mathrm{s} 3}$ are 33, 25, and 3, respectively.

Step 11: Calculate the bare wire area of each secondary, $\mathrm{A}_{\mathrm{ws} \text { n. }}$.

$$
A_{w \sin (B)}=\frac{I_{o n}}{J}
$$

Where the $I_{o n}$ is the special current of each secondary branch of the transformer, $\mathrm{A}_{\mathrm{ws} 1}=\mathrm{A}_{\mathrm{ws} 2}=$ $0.012 \mathrm{~cm}^{2}$, and $\mathrm{A}_{\mathrm{ws} 3}=0.003 \mathrm{~cm}^{2}$.

Step 12: Calculate the required number of each secondary strands, $\mathrm{S}_{\mathrm{ns}} \mathrm{n}$.

$$
S_{n s n}=\frac{A_{w s n}(B)}{\text { Bare area of selected } A W G}
$$

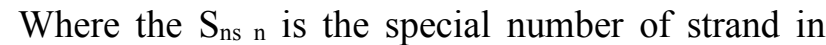
each secondary branch of the transformer, $\mathrm{S}_{\mathrm{ns} 1}=\mathrm{S}_{\mathrm{ns} 2}$ $=\mathrm{S}_{\mathrm{ns} 3}=1$.

\subsubsection{Design of the Snubber Circuit}

The flyback converter has the disadvantage of large transient voltage spikes at the drain or collector of the power switch and at the secondary rectifier. These spikes are a function of the leakage inductance in the flyback transformer. To avoid these problems, a snubber circuit should be used in order to control the effects of the leakage inductance and improve the reliability of the power supply.

A proposed resistor-capacitor-diode (RCD) type is used as a snubber circuit to absorb the current in the leakage inductor once the drain voltage exceeds the clamp capacitor voltage, the power dissipation across the resistor is calculated as:

$$
P_{\text {clamp }}=0.5 \times L_{\text {le a k a } \text { e }} \times I_{p}^{2} \times f_{s} \times \frac{V_{\text {clamp }}}{V_{\text {clamp }}-V_{r}}
$$

Where $L_{\text {leakage }}$ is the leakage inductance, $I_{p}$ is the primary current, $V_{\text {clamp }}$ is the sum voltage of $V_{\text {spike }}$ and $\mathrm{V}_{\mathrm{r}}$ that appearing across the IGBT [13].

The resistor and capacitor values of the snubber are calculated as:

$$
\begin{gathered}
R_{\text {clam } p}=\frac{V_{\text {clam } p}^{2}}{P_{\text {clam } p}} \\
C_{\text {clam } p}=\frac{V_{\text {clam } p}}{10 \times R_{\text {clam } p} \times f_{s}}
\end{gathered}
$$

The values of $\mathrm{R}_{\text {clamp, }}, \mathrm{C}_{\text {clamp, }} \mathrm{P}_{\text {clamp }}$ are $4.7 \mathrm{~K} \Omega$, $0.1 \mu \mathrm{F}, 1 \mathrm{~W}$, respectively.

\subsubsection{Design of Feedback for the Flyback Converter}

The Third secondary-side of output voltage (12 V) is fed back to the primary-side by using TL431 and the optocoupler. The output of the optocoupler, $\mathrm{V}_{\text {СOMP, is }}$ compared with the primary-side peak current through LT1241 IC driving circuit. This result constitute the negative feedback to the loop and then determines the duty cycle of the IGBT.

The open-loop transfer function of the flyback converter is given by [18]:

$$
P(s)=G \times \frac{\left(1-\frac{s}{\omega_{E S R}}\right)\left(1+\frac{s}{\omega_{R H P}}\right)}{\left(1-\frac{s}{\omega_{P}}\right)^{2}}
$$

The double poles locations are calculated as [18]:

$$
f_{p}=\frac{1}{2 \pi \sqrt{L_{e} \times C_{o}}}
$$

The right half-plane zero location is calculated as [18]:

$$
f_{Z-R H P}=\frac{1}{2 \pi \times L_{e} \times n^{2} \times D_{\max }}
$$

The electrical series resistance (ESR) zero location is calculated as [18]:

$$
f_{Z-E S R}=\frac{1}{2 \pi \times E S R \times C_{o}}
$$


The bandwidth of the system with an open-loop crossover should be limited, it can be calculated as [18]:

$$
f_{\text {Cross }}=\frac{f_{Z-R H P}}{8}
$$

The schematic of feedback circuit is demonstrated in Fig.2. Select $R_{\mathrm{f} 1}=3.8 \mathrm{k} \Omega$ and $\mathrm{R}_{\mathrm{f} 2}=1 \mathrm{k} \Omega$ in order to provide $2.5 \mathrm{~V}$ from $12 \mathrm{~V}$ at the reference pin of TL431. By using the previous equations the $\mathrm{C}_{\mathrm{f}}=$ $885 \mathrm{nF}$. Also, select $\mathrm{R}_{1}=1 \mathrm{k} \Omega$ by taking into consideration the minimum forward diode current of $4 \mathrm{n} 25$ optocoupler and minimum bias current of TL431. In addition, $\mathrm{R}_{2}=1 \mathrm{k} \Omega$ considering the current transfer ratio of $4 \mathrm{n} 25$ is equal to 0.5 .

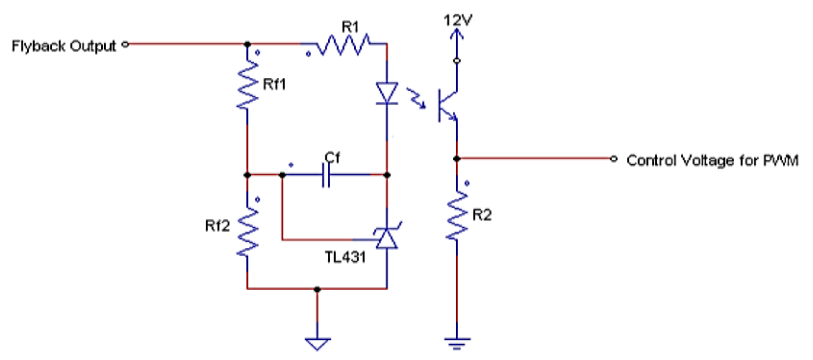

Fig.2: The schematic diagram of feedback for flyback converter

\subsubsection{Simulation of Power Supply of Solar Simulator}

\subsubsection{Modeling of LEDs in LTSPICE}

The LED is consisting of a dynamic resistance and a threshold voltage in series that explained in [19]. Then, the LED load current-voltage model would be as follows [19]:

$$
V_{d}=R_{d i} I_{d}+V_{\gamma i}
$$

Where $R_{d i}$ is the dynamic resistance, $I_{d}$ is the LED forward current, $\mathrm{V} \gamma i$ is the threshold voltage, and $\mathrm{V}_{\mathrm{d}}$ is the forward voltage drop of the LED.

The SPICE circuit simulation program provides for modeling diodes in circuit simulations. By using the default values of diodes that demonstrated in Table 3.7 in [20], it became possible to model the different types of LEDs in the LT SPICE program.

\subsubsection{Simulation of Power Supply using LTSPICE}

The triple outputs flyback converter with a single input source is simulated using the LTspice program. The transformer is consists of four inductors $\mathrm{L}_{1}, \mathrm{~L}_{2}, \mathrm{~L}_{3}, \mathrm{~L}_{4}$ that are equal to $13.41 \mathrm{mH}$, $1.774 \mathrm{mH}, 1.035 \mathrm{mH}$, and $19.7 \mu \mathrm{H}$, respectively. The output pulse width modulation (PWM) signal is generated by LT1241 IC to drive the gate of the IGBT, the maximum duty cycle at which the converter operates is 0.49 . The value of $\mathrm{C}_{2}, \mathrm{C}_{3}$, and $\mathrm{C}_{4}$ are equals to $220 \mu \mathrm{F}$ that used to filter the triple output power from ripples respectively. The schematic diagram of the open loop power supply circuit is demonstrated in Fig.3.

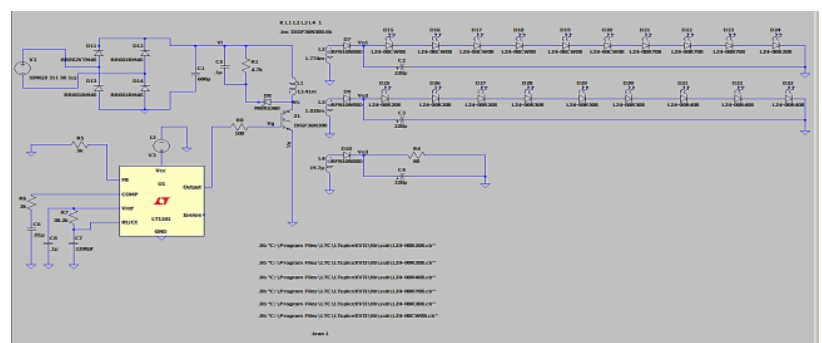

Fig.3: The schematic diagram of open loop power supply

The output simulation waveforms of the voltage and the current for the power supply are taken at the desired loads that demonstrated in Fig.4 and Fig.5. From these figures, the observed output voltage and current are $\mathrm{V}_{\mathrm{o} 1}=120 \mathrm{~V}, \mathrm{I}_{\mathrm{o} 1}=0.8 \mathrm{~A}, \mathrm{~V}_{\mathrm{o} 2}=90 \mathrm{~V}, \mathrm{I}_{02}=$ $0.8 \mathrm{~A}, \mathrm{~V}_{03}=12 \mathrm{~V}, \mathrm{I}_{03}=0.2 \mathrm{~A}$. The results of simulation have achieved the required voltage and current in each branch of the power supply.

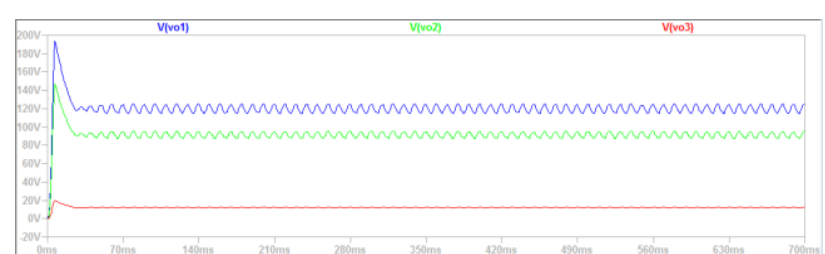

Fig.4: The output voltage of open loop power supply

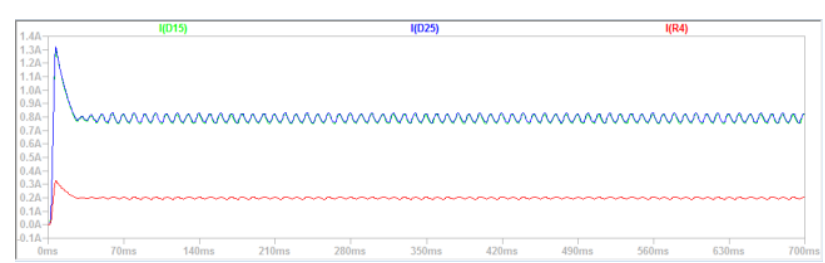

Fig.5: The output current of the open loop power supply

The closed loop circuit of the power supply simulation is carried out using TL431 and LT1241 controller IC. The schematic of the power supply with the closed loop circuit used for simulation is shown in Fig.6. Figures 7-14 show the waveforms of voltage and current at different loading 
conditions (full load, half load, 2/3 ${ }^{\text {th }}$ load). The results prove that the feedback circuit have operated efficiently and fixed the three output voltages by adjusting the duty cycle during input and load variation.

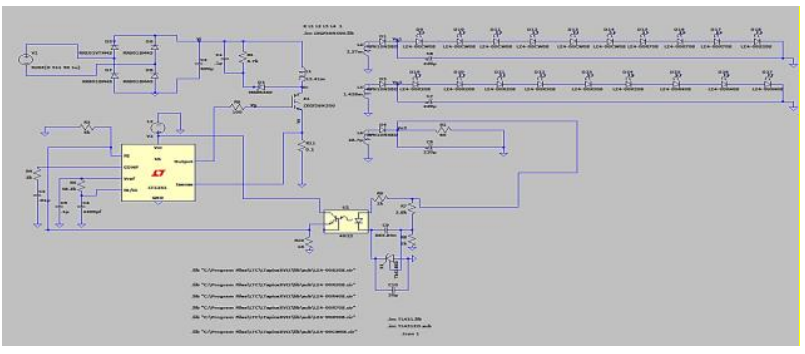

Fig.6: The schematic diagram of closed loop power supply at full load

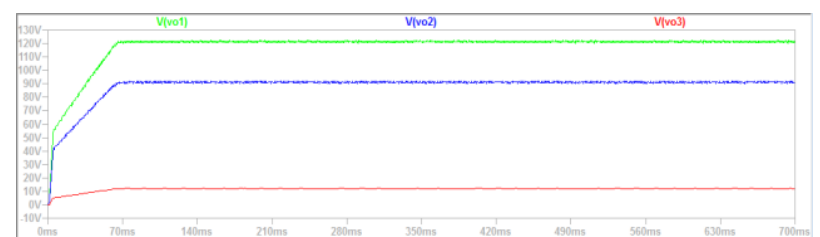

Fig.7: The output voltage of closed loop power supply at full load

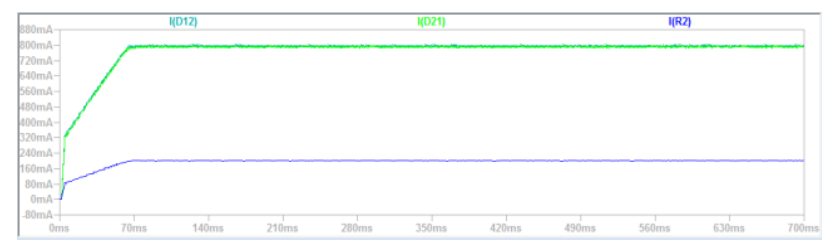

Fig.8: The output current of closed loop power supply at full load

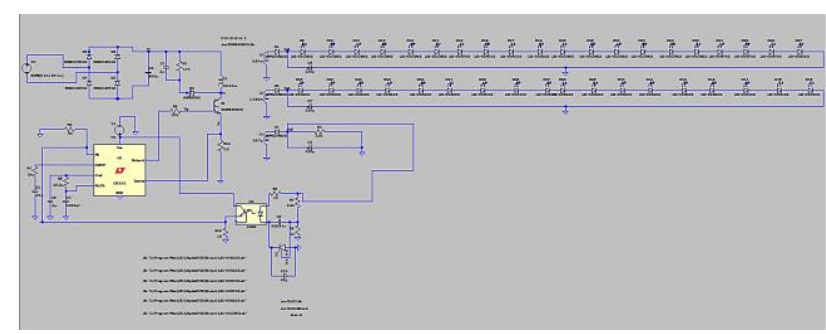

Fig.9: The schematic diagram of closed loop power supply at double load

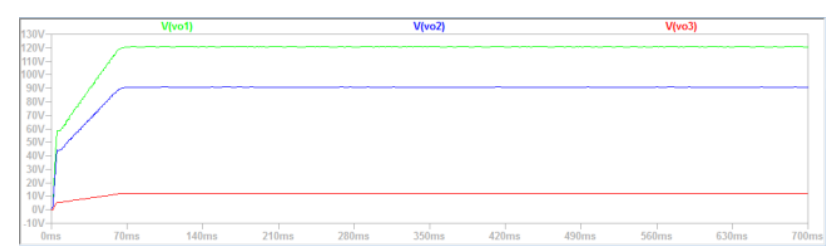

Fig.10: The output voltage of closed loop power supply at double load

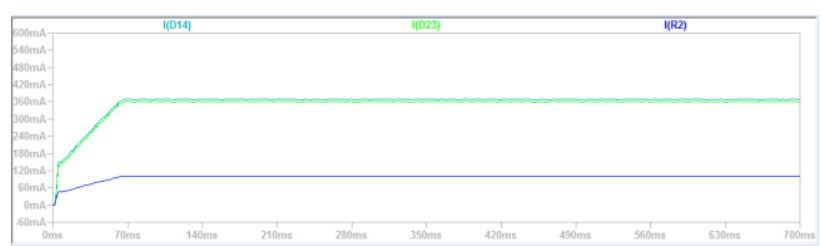

Fig.11: The output current of closed loop power supply at double load

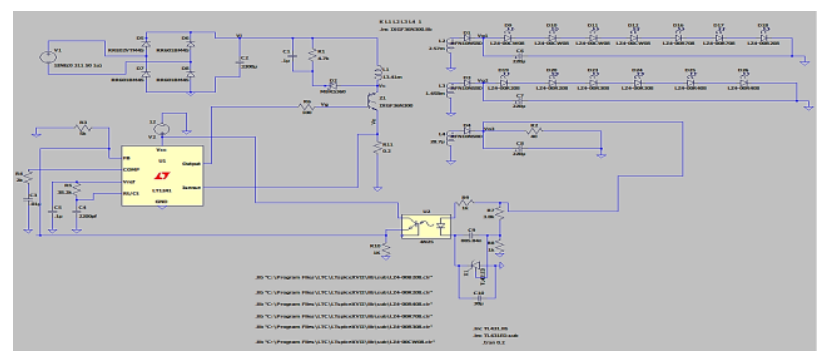

Fig.12: The schematic diagram of closed loop power supply at $2 / 3^{\text {th }}$ load

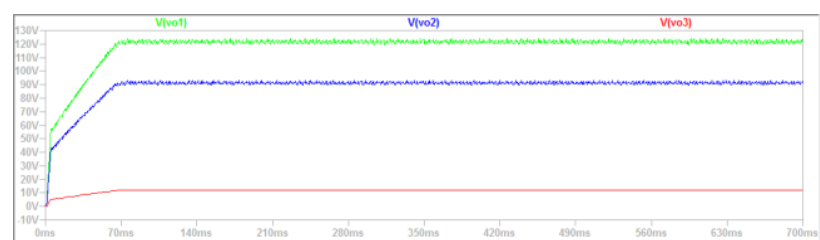

Fig.13: The output voltage of closed loop power supply at $2 / 3^{\text {th }}$ load

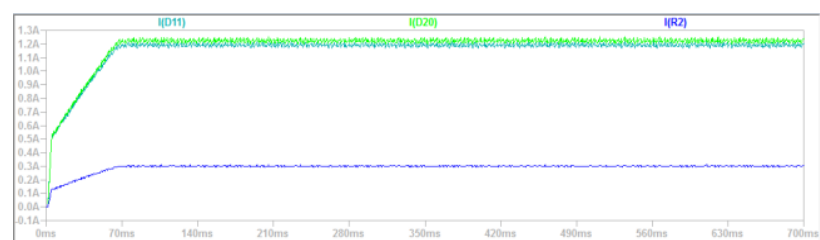

Fig.14: The output current of closed loop power supply at $2 / 3^{\text {th }}$ load

\subsection{Temperature Control of the Solar Simulator}

Solar cells characteristics and efficiency measurements should be done at STC. Therefore, temperature control is necessary to fix it in the range from $24.8{ }^{\circ} \mathrm{C}$ to $25.2{ }^{\circ} \mathrm{C}$. In this paper, a PID controller is used to adjust the required temperature. The flowchart of temperature control for solar simulator is demonstrated in Fig. 15.

Firstly, the temperature is measured by using the sensor and then compare the measured temperature value with the set point of temperature to calculate the error. If the error is equal to zero, it means that the system is ready to test. Otherwise, if the error is not equal to zero then it should be applying the PID controller to adjust the temperature at the set point. If the temperature is larger than the set point, the fan begins operating, however, if the temperature is 
lower than the set point, the heater starts operating and then measure the temperature of the system once again. These steps repeated until reach the required temperature.

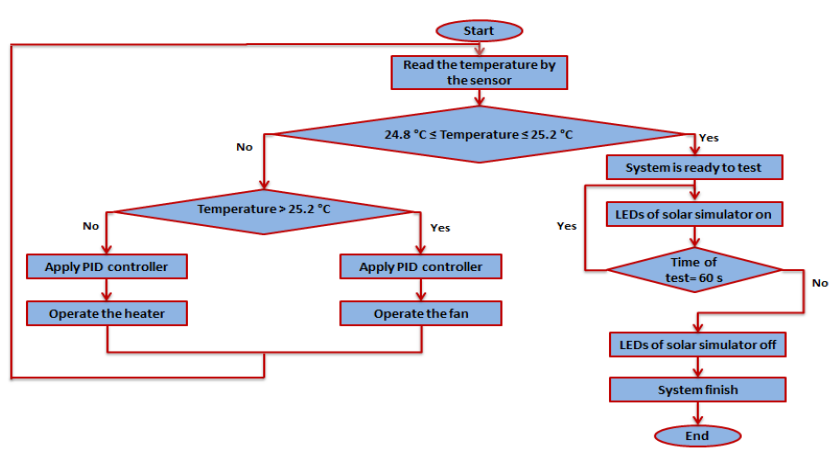

Fig.15: The flowchart of temperature control for the solar simulator

\section{Experimental Results}

\subsection{The LED Light Source of Solar Simulator}

The distribution of 19 LEDs of the solar simulator is illustrated in Fig. 16. These LEDs are mounted on individual hexagonal star type metalcore printed circuit boards (MCPCB), which arranged in the form of honeycomb cluster to ensure optimal flux homogeneity and are gathered on an aluminum rectangular plate. A plate with LEDs is mounted on an aluminum heat sink. The distance between each LED's centers to all nearby LEDs centers is approximately $20 \mathrm{~mm}$.

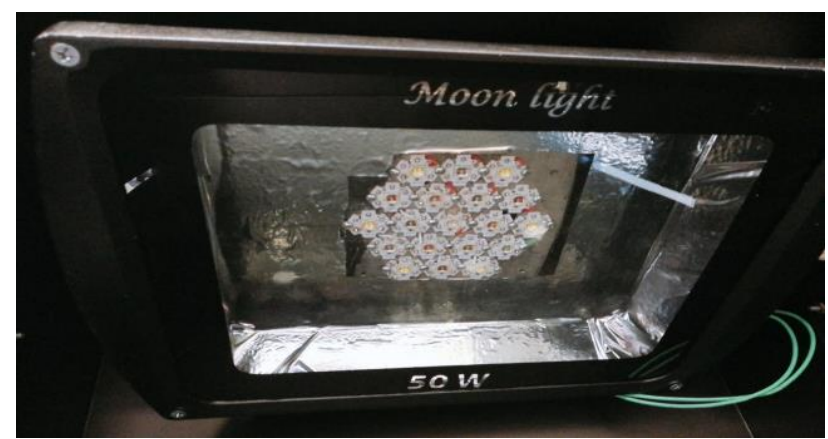

Fig.16: The distribution structure of LEDs for solar simulator

\subsection{The power Supply of Solar Simulator}

Bridge rectifier KBPC 3510 is used to convert from AC input voltage $(220 \mathrm{~V})$ to DC output voltage $(311 \mathrm{~V})$. The DC link capacitor is used to mitigate the ripple of the DC output by using four parallel LGU2W391MELC nichicon capacitors, where each capacitor is equal to $390 \mu \mathrm{F}$. The output $\mathrm{DC}$ voltage of this converter is $311 \mathrm{~V}$ and the ripple voltage is less than $3 \%$ shown in Fig. 17.

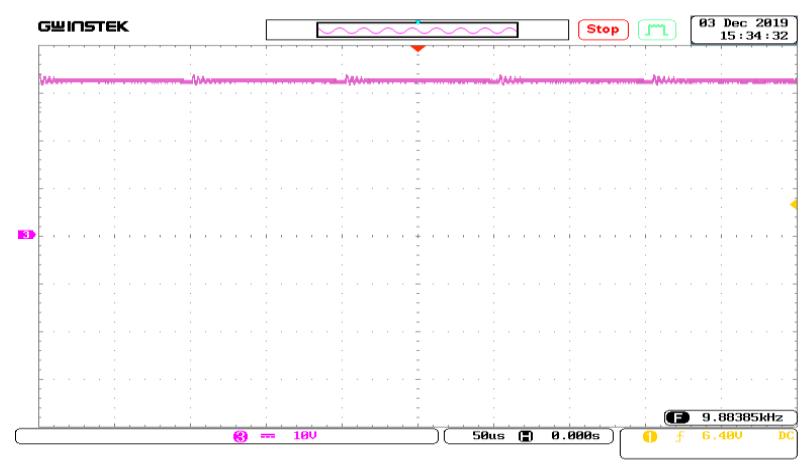

Fig.17: The output voltage of AC to DC converter

A transformer is designed by using ETD 59 ferrite core, the primary winding is placed innermost on the bobbin, which the number of primary turns is 85 turn, and then the secondary windings are placed close to the primary side winding on the next layers, where the number of each secondary turns is $33,25,3$, respectively. IRG4PH50UDPBF IGBT transistor is used as the converter switch. The PWM current regulator LT1241 is used to drive the gate of IGBT, where the circuit is operating at frequency switching 10 $\mathrm{kHz}$ and the maximum duty cycle sets to be 0.49 . To limit the voltage spike on the IGBT, when the IGBT is turned off an RCD clamp is implemented, where $\mathrm{R}, \mathrm{C}, \mathrm{D}$ are $4.7 \mathrm{~K} \Omega, 0.1 \mu \mathrm{F}, \mathrm{BY} 329$ fast diode, respectively.

Three BY329 fast rectifier diodes are placed on each secondary side. At the output sides of the converter, several electrolytic and polyester capacitors in parallel are usually used to achieve a very low output ripple voltage in each secondary side. The simplest linear way to model the LEDs to test the power supply through account only the equivalent resistance of the LEDs at the nominal operating point [17]. Figure 18 shows the hardware setup of the power supply.

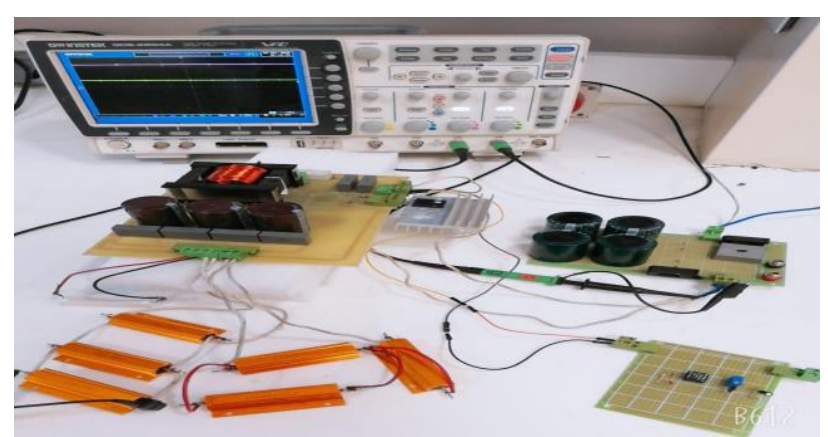

Fig.18: Experimental of the power supply 
Figures 19, 20, and 21 show the voltage waveforms of the converter obtained by measurement data for a specific operating point in CCM.

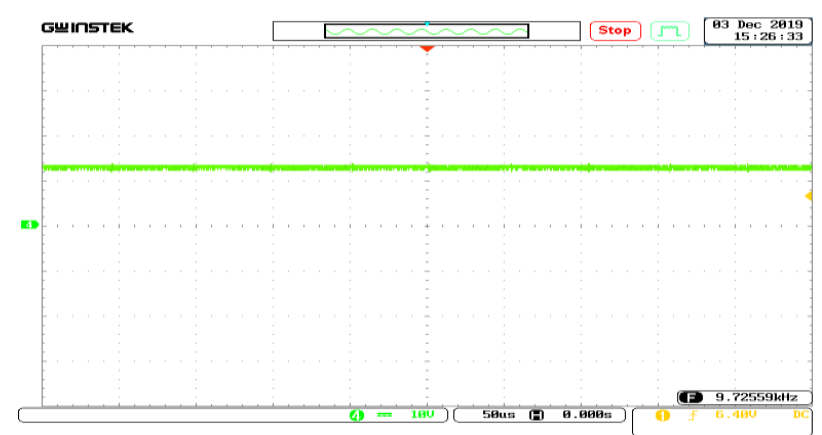

Fig.19: The output voltage of the first secondary. Scale: $100 \mathrm{~V} / \mathrm{div}$

The output voltages $\mathrm{V}_{\mathrm{o} 1}, \mathrm{~V}_{\mathrm{o} 2}$, and $\mathrm{V}_{\mathrm{o} 3}$ are $120 \mathrm{~V}, 90$ $\mathrm{V}$, and $12 \mathrm{~V}$, respectively.

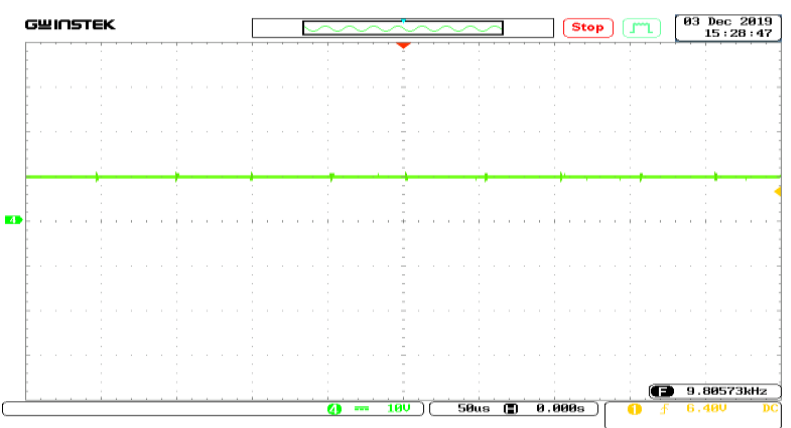

Fig.20: The output voltage of the second secondary

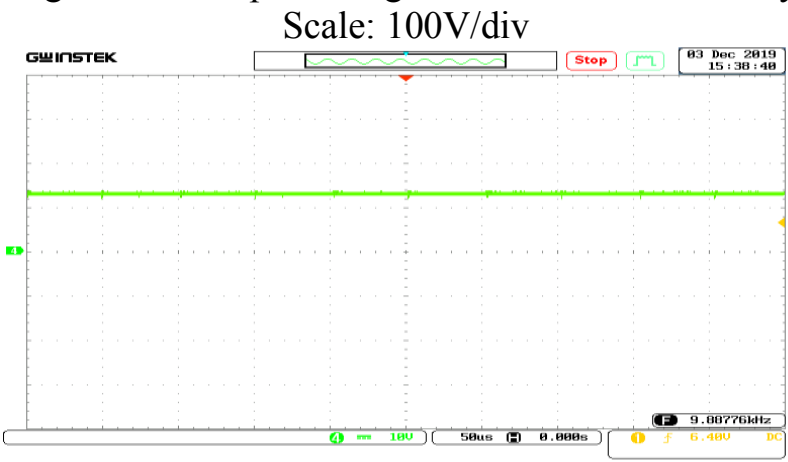

Fig.21: The output voltage of the third secondary Scale: $10 \mathrm{~V} / \mathrm{div}$

\subsection{The Temperature Control of the Solar Simulator}

The DHT11 sensor is used to measure the temperature and send data to Arduino mega 2560. If both values are the same, the error will be 0 . Otherwise, if the measured value is different than the set point, the PID control is activated according to the parameters, which the $\mathrm{K}_{\mathrm{p}}, \mathrm{K}_{\mathrm{i}}, \mathrm{K}_{\mathrm{d}}$ are 90,10 , 50 , respectively. In both cases, the output will be sent to Arduino to establish an action. If the measured value is smaller than the set point of temperature (24.8-25.2) ${ }^{\circ} \mathrm{C}$, the Arduino sends the signal to operate heater by solid-state relay. Otherwise, if the measured value is larger than the set point of temperature, the Arduino sends the signal to operate the fan by L298 module dual Hbridge. These steps are repeated until reach the required temperature. Fig.22 demonstrates the temperature control by using Arduino.

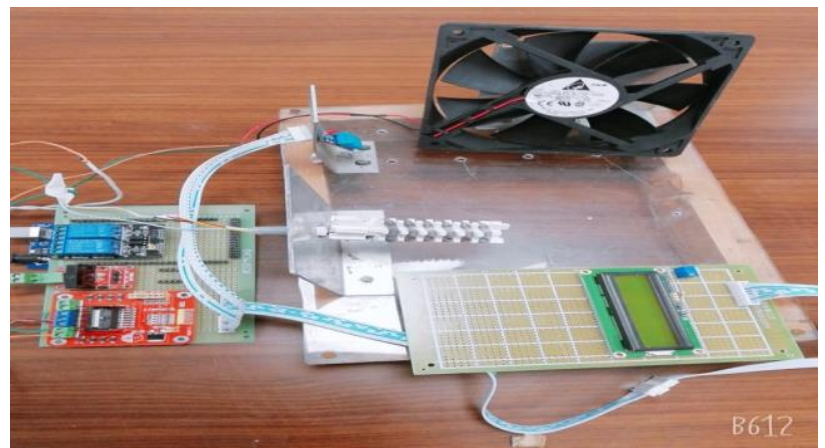

Fig.22: Temperature control using Arduino

\subsection{The Complete System of the LED Solar Simulator}

A 6 of cool white LEDs (LZ4-00CW08), 1 blue LED (LZ4-00B208), and 3 IR LEDs (LZ400R708) are connected in series at the first output branch of power supply $(120 \mathrm{~V})$. At the second branch of the power supply $(90 \mathrm{~V})$, a 3 deep red LEDs (LZ400R208), 3 far-red LEDs (LZ4-00R308), and 3 IR LEDs (LZ400R408) are connected also in series.

By using Arduino the PID controller is used to control the temperature to achieve the required temperature. If the temperature is reached to the required value the relay module operates the LEDs, the system is on for 60 seconds to test the solar cell illustrates in Fig.23. If the specified time for the test is finished the LEDs are off and display the status of the system on the LCD as shown in Fig.24.

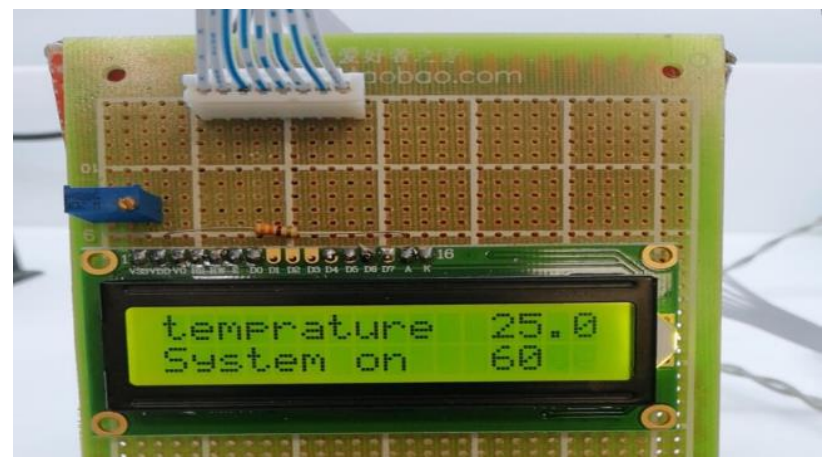

Fig.23: The status of the system when the temperature is reached to 25 


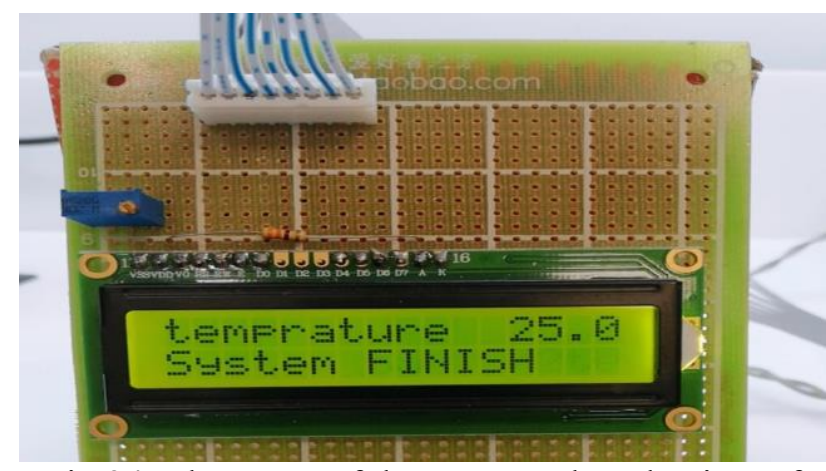

Fig.24: The status of the system when the time of the test is finish

By using national institute for standards, the ocean optics spectroradiometer HR 2000 is used to measure the spectrum of the LEDs for solar simulator shown in Fig.25. The experimental spectrum of LED solar simulator is demonstrated in Fig.26. Figure 27 gives the theoretical and experimental spectrums of the proposed LED solar simulator. It is clear that there are many peaks in the spectrum exceed AM 1.5G; by using Air Mass 1.5 global filter these peaks are removed. Results show that experimental spectrum and theoretical spectrum of the proposed solar simulator is near to the spectrum of the sun in the majority of visible range but the experimental spectrum of the solar simulator in the infra-red range is weaker especially from 800 $\mathrm{nm}$ to $1100 \mathrm{~nm}$. So that, the number of LEDs in the infra-red range and some regions of the spectrum should be increased to get the same spectrum of the sun in the future.

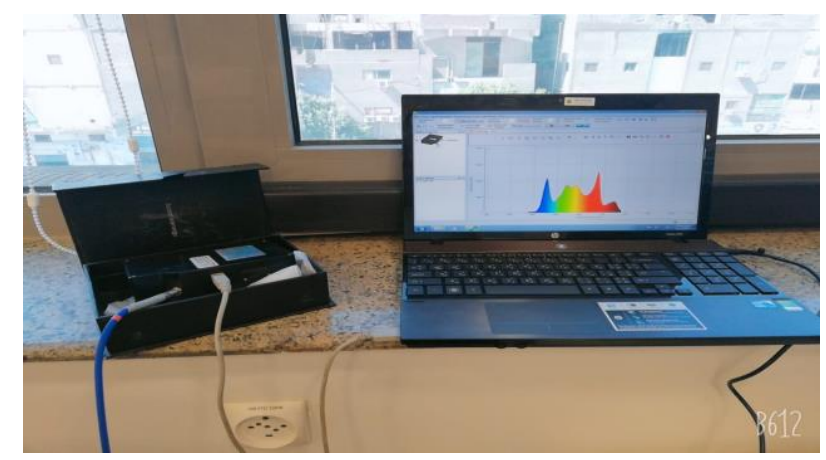

Fig.25: Measuring the spectrum of LEDs using ocean spectroradiometer

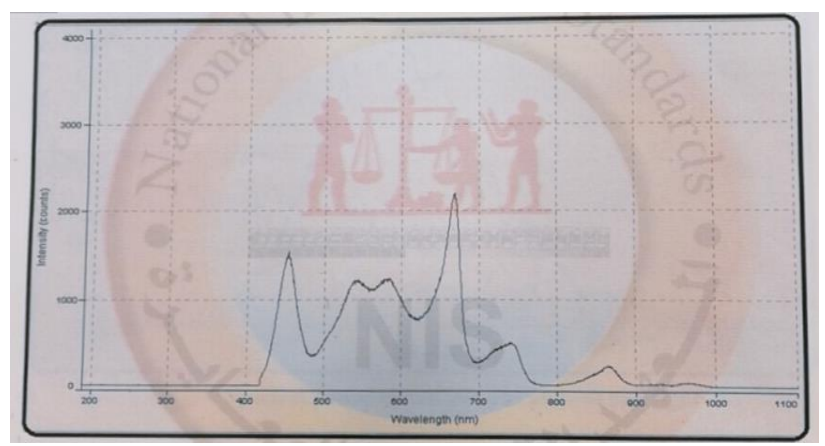

Fig.26: The output spectrum of LEDs using ocean spectroradiometer

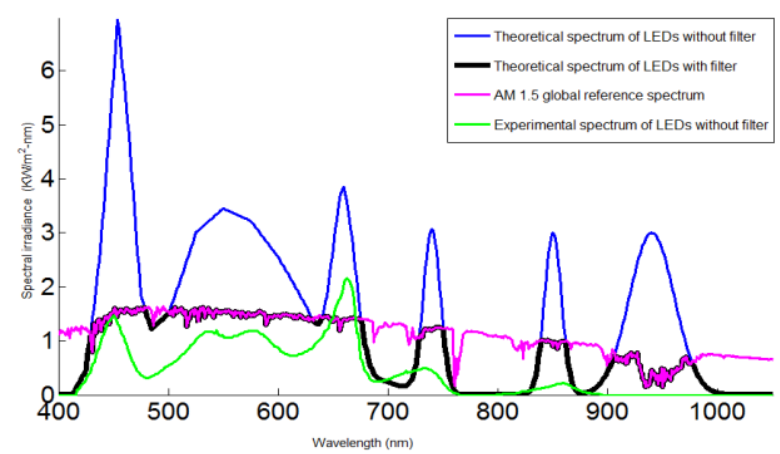

Fig. 27: The experimental output spectrum with the theoretical spectrum of LEDs and AM $1.5 \mathrm{G}$ spectrum

\section{Conclusion}

This paper presented a complete design of LED based solar simulator. A complete design of the LED light source based solar simulator has been built to cover the AM 1.5G solar spectrum. A prototype of the LED solar simulator was developed simulated, implemented, and tested using 19 types of LEDs from 6 different wavelengths that cover the visible and partial from the IR spectrum. Also, three multiple-output flyback converter was designed and developed for a wide AC input voltage range of 85 $\mathrm{V}-230 \mathrm{~V}$, with $170.4 \mathrm{~W}$ full load output power. The designed power supply was simulated by using LTspice program and the relevant waveforms were obtained. The experimental result thus obtained agrees with the simulation results. Moreover, in this paper, the temperature control based PID controller for the solar simulator was designed and implemented by using Arduino Mega 2560. The results of temperature control unit Proved that the PID controller adjusted the required temperature successfully.

\section{References:}

[1] S. Pilakkat, "Study of the Importance of MPPT Algorithm for Photovoltaic Systems under Abrupt Change in Irradiance and Temperature 
Conditions," WSEAS Trans. Power Syst., vol. 15, 2020.

[2] E. López-Fraguas, J. Sánchez-Pena, and R. Vergaz, "A Low-Cost LED-Based Solar Simulator," IEEE Trans. Instrum. Meas., pp.4913-4923, 2019.

[3] M. Tawfik, X. Tonnellier, and C. Sansom, "Light source selection for a solar simulator for thermal applications: A review," Renew. Sustain. Energy Rev., vol. 90, pp. 802-813, 2018.

[4] V. Esen, Ş. Sağlam, and B. Oral, "Light sources of solar simulators for photovoltaic devices: A review," Renew. Sustain. Energy Rev., vol. 77, pp. 1240-1250, 2017.

[5] R. Salam, M. Munir, T. Warsahemas, C. Saputra, H. Latief, and K. Khairurrijal, "A simple solar simulator with highly stable controlled irradiance for solar panel characterization," Meas. Control, vol. 52, no. 3-4, pp. 159-168, 2019.

[6] J. Jin, Y. Hao, and H. Jin, "A universal solar simulator for focused and collimated beams," Appl. Energy, vol. 235, pp. 1266-1276, 2019.

[7] G. Dibowski and K. Esser, "Hazards caused by UV rays of xenon light based high performance solar simulators," Saf. Health Work, vol. 8, no. 3, pp. 237-245, 2017.

[8] G. Switzer, T. McFarland, Buczala, P. Rishel, and E. Kuntz, "LED-Based solar simulator system and method of use." Google Patents, 09-Oct-2018.

[9] F. Plyta, "Optical design of a fully LED-based solar simulator." Foteini Plyta, 2015.

[10] W. Wang and B. Laumert, "Simulate a 'sun'for solar research: a literature review of solar simulator technology." KTH Royal Institute of Technology, 2014.

[11] G. Grandi and A. Ienina, "Analysis and realization of a low-cost hybrid LED-halogen solar simulator," in 2013 International Conference on Renewable Energy Research and Applications (ICRERA), pp. 794-799, 2013.

[12] A. Johnston, M. Johnson, J. Sweat, and A. ElShahat, "Small-Scale Electric Vehicle DC-DC Converter for Nano-Grids Applications," WSEAS Trans. Power Syst., vol. 12, p. 134, 2017.

[13] U. Padiyar and V. Kamath, "Design and implementation of a universal input flyback converter," in 2016 International Conference on Electrical, Electronics, and Optimization Techniques (ICEEOT), pp. 3428-3433, 2016.
[14] J. Picard, "Under the hood of flyback SMPS designs," in Texas Instruments Power Supply Design Seminar, pp. 245-250, 2010.

[15] Fairchild Semiconductor Corporation, "Design Guidelines for Flyback Converters Using FSQseries Fairchild Power Switch (FPSTM)." pp. 1-16, 2006.

[16] W. Colonel, "T. McLyman Transformer and inductor design Handbook Third Edition, Revised and Expanded Kg Magnetics," Inc. Idyllwild, California, USA, 2004.

[17] M. Zahran, "Design, implementation and testing of HF transformers for satellite EPS applications," J. Power Electron., vol. 8, no. 3, pp. 217-227, 2008.

[18] S. Raghunathan, "Isolated Multiple Output Flyback Converter Design Using TL494," Texas Instruments, Tech. Rep. SLVA666, 2014.

[19] M. Ali, M. Orabi, M. Ahmed, and A. El Aroudi, "Design considerations of a singlestage LED lamp driver with power factor correction," in 2011 2nd International Conference on Electric Power and Energy Conversion Systems (EPECS), 2011, pp. 1-6.

[20] T. Kuphaldt, "Lessons In Electric Circuits, Volume III-Semiconductors." 2009. 